\title{
ALUNOS COM TEA COMO DESENCADEADORES DE PROCESSOS FORMATIVOS
}

\section{ALUMNOS CON TEA COMO PROVOCADORES DE PROCESOS FORMATIVOS}

\author{
STUDENTS WITH AUTISM SPECTRUM DISORDER AS TRIGGERS OF \\ TRAINING PROCESSES
}

\author{
Sandra Cordeiro de MELO ${ }^{1}$ \\ Mylene Cristina SANTIAGO ${ }^{2}$
}

\begin{abstract}
RESUMO: Este estudo busca refletir sobre como os alunos com TEA podem desencadear mudanças nos processos formativos nas escolas regulares para facilitar a aprendizagem de todos os alunos. Apresenta a evolução da nosologia do TEA considerando que o professor deve conhecer cada aluno para que possa acompanhar o seu processo de aprendizagem e, se distanciar o suficiente para perceber as demandas da turma. Busca, em uma pesquisa realizada com professores de escolas de ensino fundamental do Estado do RJ, analisar relatos sobre suas atuações em sala quando nesta participa pelo menos um aluno com TEA. Propõe que as tecnologias assistivas, utilizadas e conhecidas principalmente pelos professores da Educação Especial, podem servir de poderoso instrumento quando utilizadas pelo professor da sala de aula regular.
\end{abstract}

PALAVRAS-CHAVE: Transtorno do espectro autista. Tecnologias assistivas. Processo ensino-aprendizagem.

RESUMEN: Este estudo busca reflexionar sobre cómo los alumnos con TEA pueden desencadenar cambios en los procesos formativos en las escuelas regulares para facilitar el aprendizaje de todos los alumnos. Se presenta la evolución de la nosología del TEA considerando que el profesor debe conocer a cada alumno para que pueda acompañar su proceso de aprendizaje y, si distanciarse lo suficiente para percibir las demandas de la clase. En una investigación realizada con profesores de escuelas de enseñanza fundamental del Estado de RJ, analiza relatos sobre sus actuaciones en sala cuando en ésta participa al menos un alumno con TEA. Propone que las tecnologías asistivas, utilizadas y conocidas principalmente por los profesores de Educación Especial, pueden servir de poderoso instrumento cuando son utilizadas por el profesor de la classe regular.

PALABRAS CLAVE: Trastorno del espectro autista. Tecnologías asistivas. Proceso enseñanza-aprendizaje.

\footnotetext{
${ }^{1}$ Universidade Federal do Rio de Janeiro (UFRJ), Rio de Janeiro - RJ - Brasil. Professora Adjunta do Departamento de Fundamentos da Educação. ORCID <https://orcid.org/0000-0002-8437-1671>. E-mail: sandracmello@gmail.com

${ }^{2}$ Universidade Federal de Juiz de Fora (UFJF), Juiz de Fora - MG - Brasil. Professora Adjunta do Departamento de Educação. ORCID <https://orcid.org/0000-0003-2769-8421>. E-mail: mylenesantiago87@gmail.com
} 
ABSTRACT: This study aims to reflect on how the students with autism spectrum disorder can trigger changes in the training processes in regular schools so as to facilitate all the students' learning. It presents the evolution of the autism spectrum disorder nosology by taking into consideration that the teacher must know each student in order to follow his or her learning process. This nosology also considers that the teacher must distance himself or herself enough to perceive the class demands. The chapter seeks to analyse reports from a research with teachers at elementary schools in the state of Rio de Janeiro. The reports are related to those teachers' performances in classrooms with at least one student with autism spectrum disorder. It proposes that the assistive technologies, which are used and known mainly by the Special Education teachers, can serve as powerful tools when used by the regular classroom teacher.

KEYWORDS: Autism spectrum disorder. Assistive technologies. Teaching-learning process.

\section{Introdução}

Se a prática pedagógica é construída prioritariamente a partir do desenvolvimento da criança sem necessidades educacionais permanentes, como educar crianças com o desenvolvimento diferenciado e com necessidades educacionais tão específicas? Será esta prática válida para nortear a educação de uma escola que precisa educar a todos?

A sala de aula é um misto de habilidades. Cada aluno possui as suas. O desafio do processo de ensino e de aprendizagem é buscar meios para desenvolver tanto as que ele já tem como as que ainda não desenvolveu. Entendemos que a escola tem uma tarefa dupla: focar tanto as habilidades já adquiridas como desenvolver novas. Mas para cumprir tal tarefa, precisará, antes, conhecê-las.

Perrenoud (2001, p. 19) expõe sobre a responsabilidade da escola. Segundo o autor, o sistema escolar é responsável pelos índices de fracasso escolar à medida que, cada criança deve nela permanecer de 25 a 35 horas por semana, durante pelo menos 10 anos, sujeito à sua ação pedagógica. O autor propõe uma pergunta: se a escola dispõe de tanto poder sobre as pessoas, porque não consegue instruí-las? E continua: para que serve ir à escola 9 ou 10 anos, se alguns saem dela sem ler fluentemente? Segundo o autor, a indiferença às diferenças é princípio gerador de fracasso escolar.

O autor não faz distinção entre alunos com ou sem necessidades especiais, o que nos leva a considerar que o exercício da diferenciação é para todos. Entendemos que diferenciar alunos diz respeito a conhecer cada um deles, seu processo de desenvolvimento, sua história pessoal, seus gostos, sua maneira de ser e de agir, o som 
da sua voz, a cor do seu cabelo, o tom da sua pele, o ritmo do seu raciocínio, sua oratória. O desconhecimento deste aluno, ou de aspectos relacionados ao seu desenvolvimento, seja no campo cognitivo, afetivo, emocional, tende a erigir barreiras entre o seu aprendizado e à ação pedagógica da escola.

Neste trabalho buscaremos refletir sobre a importância de construir sentido na ação pedagógica, de forma particular, mas sem perder a dimensão do geral. Partimos do princípio de que educar é um ato intencional e que aprender é subjetivo. Cada sujeito absorve as informações que julga procedente dentro de seu universo de associações. $\mathrm{O}$ professor atento a este processo se coloca tão próximo de seus alunos de modo que possa acompanhar o seu raciocínio e distante o suficiente para perceber as demandas da turma. Certamente este é um desafio para a educação em tempos de precarização do ensino.

\section{Alunos com TEA: desafios para o sistema escolar}

Quais respostas as escolas têm oferecido, conforme as necessidades específicas de alunos com TEA, no que tange à adequação curricular e alternativas metodológicas diferenciadas?

Para Baptista e Aniê (apud BAPTISTA; BOSA, 2002, p. 95) "o ato pedagógico deveria deixar de ser uma decorrência do processo diagnóstico, passando a integrar um movimento de investigação que explora a pergunta: quem é esse sujeito?" Entendemos que trabalhar em prol de uma educação mais inclusiva supõe que consideremos o “todos" e não apenas uma parcela.

A nosologia do Transtorno do Espectro Autista vem sofrendo mudanças. Em 1911, Eugen Bleuler descreveu o que chamou de Síndrome da Esquizofrenia Infantil, enfatizando como sintoma principal a Spaltung ou Dissociação. Nestas crianças, predominava o estado "fora da realidade" e o de ensimesmamento. Era o que ele chamava de autismo - autos, em grego, significa em si mesmo. O Transtorno Autista foi descrito, inicialmente, pelo psiquiatra austríaco, Leo Kanner em seu artigo intitulado Alterações autísticas do contato afetivo, publicado em 1943.

Kanner descreve e comenta os casos de onze crianças que apresentavam um quadro de distúrbio do desenvolvimento caracterizado por incapacidade de estabelecer relações pessoais, um conjunto de atrasos e alterações na aquisição e uso da linguagem 
e uma "insistência obsessiva" em manter o ambiente imutável, acompanhada da tendência a repetir uma gama limitada de atividades ritualizadas.

Estes sintomas, segundo Kanner, surgiam muito precocemente (nos casos em que estudou, surgiram desde o nascimento). Seu trabalho sugere que estas crianças poderiam ter um "bom potencial cognitivo", baseando-se em sua fisionomia inteligente, algumas habilidades especiais (sobretudo a memória mecânica) e na execução de um teste psicométrico de caráter visual-espacial. Kanner definiu o autismo infantil precoce da seguinte maneira:

O excepcional, [...] a desordem fundamental é a inaptidão das crianças a estabelecer relações normais com pessoas e a reagir às situações desde o início da vida. Os pais referem-se a eles como tendo sempre sido autossuficientes, como em uma concha, agindo como se ninguém estivesse presente, perfeitamente esquecidos de tudo ao seu redor, dando a impressão de uma sabedoria silenciosa, faltando desenvolver a quantidade habitual de consciência social, agindo como se estivessem hipnotizados [...] (BERQUEZ, 1983 apud AMY, 2001, p. $31)$.

Segundo Berquez, nesta descrição, Kanner supôs um distúrbio primário semelhante ao descrito para a esquizofrenia, mas diferenciou-os ao considerar que a criança autista não realiza um fechamento sobre si mesma e sim, busca estabelecer uma espécie de contato bastante particular e específico com o mundo. Mesmo sendo semelhantes, Kanner postulava que os dois quadros deveriam ser vistos como distintos. Ainda que o artigo de Kanner tenha sido decisivo para definir o autismo como um transtorno independente, não foi o primeiro em que se descreviam crianças com essas características. Diversos estudos foram realizados no intuito de conhecer origem para o transtorno dentro do histórico das perturbações mentais (FACION, 2002, p. 11).

Segundo Rivière,

Desde a antiguidade, conhecem-se relatos de crianças, ou adultos com comportamentos estranhos, que podem relacionar-se com o autismo. Mais claramente, ao longo dos séculos XVIII e XIX, e em relação às ideias sobre o papel da natureza, da educação e da cultura na definição da psicologia humana - estimuladas por filósofos como Locke e Rousseau - desenvolveu-se um interesse em conhecer casos de crianças com perturbações graves das capacidades de interação e contato afetivo. (2004, p. 241). 
Com o passar dos anos, estudos demonstraram que o autismo caracteriza-se por dificuldades importantes na capacidade em estabelecer relações, na comunicação e no contato com o meio.

Em 1995, a American Academy of Pediatrics (AAP) definia o Autismo como um Transtorno Global do Desenvolvimento. Este subgrupo era caracterizado por severas deficiências e prejuízos invasivos em múltiplas áreas do desenvolvimento, incluindo perdas na interação social recíproca e na comunicação, apresentando comportamentos, interesses e atividades estereotipadas.

De acordo com Wing (1996 apud BOSA, 2002 BAPTISTA; BOSA, 2002, p. 31) os estudos epidemiológicos apontavam para taxas de prevalências que variavam de 2 a 3 até 16 em cada 10 mil crianças. Em 1997, a Associação Brasileira de Autismo, divulgava um cálculo de, aproximadamente, 600 mil pessoas acometidas pelo transtorno. Com a evolução do diagnóstico, que altera a denominação de Transtorno Global do Desenvolvimento para Transtorno do Espectro Autista, das políticas públicas para a educação especial e especificamente para as pessoas com TEA, este quadro vai mudar, inclusive no que tange a sua incidência, para o espetacular número, divulgado pelo Centro de Controle e Prevenção de Doenças - CDC, dos Estados Unidos, em 2015, de 1 para cada 45 pessoas. Isto significa que, 2,25\% da população mundial estará entre as pessoas com TEA. Em 2017, a Organização Mundial de Saúde divulgou a estatística, mais modesta do que o CDC, mas ainda alarmante, de que 1 a cada 160 pessoas no mundo tem TEA. De acordo com Mello (2007, p. 17), a incidência de autismo varia de acordo com o critério utilizado por cada autor.

Em 2013, com a divulgação do Manual Diagnóstico e Estatístico das Doenças Mentais V (DSM V) a nomenclatura do então Transtorno Global do Desenvolvimento mudou para Transtorno do Espectro Autista. Não apenas a nomenclatura, mas sua nosologia também sofreu alterações. Enquanto no DSMI V o TGD era considerado um conjunto composto por Autismo, Síndrome de Asperger, Síndrome de Rett e o Transtorno Global do Desenvolvimento sem Outras Especificações, no DSM V o TEA considera o Autismo, a Síndrome de Asperger, o Transtorno Infantil Desintegrativo e o TGDSOE. A Síndrome de Rett deixa de compor este conjunto.

De acordo com a DSM V (2013) o Transtorno do Espectro Autista, fica assim definido: 
A. Déficits persistentes na comunicação social e na interação social em múltiplos contextos, conforme manifestado pelo que segue, atualmente ou por história prévia (os exemplos são apenas ilustrativos, e não exaustivos; ver o texto):

1. Déficits na reciprocidade socioemocional, variando, por exemplo, de abordagem social anormal e dificuldade para estabelecer uma conversa normal a compartilhamento reduzido de interesses, emoções ou afeto, a dificuldade para iniciar ou responder a interações sociais.

2. Déficits nos comportamentos comunicativos não verbais usados para interação social, variando, por exemplo, de comunicação verbal e não verbal pouco integrada a anormalidade no contato visual $\mathrm{e}$ linguagem corporal ou déficits na compreensão e uso gestos, a ausência total de expressões faciais e comunicação não verbal.

3. Déficits para desenvolver, manter e compreender relacionamentos, variando, por exemplo, de dificuldade em ajustar o comportamento para se adequar a contextos sociais diversos a dificuldade em compartilhar brincadeiras imaginativas ou em fazer amigos, a ausência de interesse por pares (DSM V, 2013).

Politicamente, o reconhecimento social do TEA também sofreu intensas mudanças. Passada a repercussão que as Declarações de Educação para Todos (1990) e de Salamanca (1994) tiveram sobre os cenários ainda divididos da Educação Especial, da recém gerada Educação Inclusiva.

Destacamos, inicialmente, a Política de Acesso dos Alunos com Deficiência às Escolas e Classes Comuns da Rede Regular (BRASIL, 2004); o Documento Subsidiário à Política de Inclusão (BRASIL, 2005); a Política Nacional de Educação Especial na Perspectiva da Educação Inclusiva (BRASIL, 2008).

Em 2004, o Ministério Público Federal, através da Procuradoria Federal dos Direitos do Cidadão, realizou uma série de oficinas de debates entre profissionais das áreas jurídica e pedagógica, e elaborou um documento com o objetivo de divulgar os conceitos atuais e mais adequados às diretrizes mundiais com vistas à educação para todos. Estes debates levantaram a discussão sobre a legalidade da substituição do ensino fundamental regular pelo ensino em instituições especializadas.

$\mathrm{O}$ direito ao atendimento educacional especializado previsto nos artigos 58, 59 e 60 da LDBEN, Lei 9.394/96 (BRASIL, 1996) e também na Constituição Federal (BRASIL, 1988), não substitui o direito à educação (escolarização) oferecida em classe comum da rede regular de ensino (BRASIL, 2004, p. 10).

A interpretação deste grupo é a de que a LDBEN não diz que a escolarização poderá ser oferecida em ambiente escolar à parte. Afirma que sua interpretação é a de 
que, por ser o Ensino Fundamental um direito humano indisponível, nenhuma pessoa poderia dele ser privada. Defende a educação para todos, baseado na tese de que:

O ensino para alguns é ideal para gerar indisciplina, competição, discriminação, preconceitos e para categorizar os "bons" e os "maus" alunos, por critérios que são, no geral, infundados. Já o ensino para todos desafia o sistema educacional, a comunidade escolar e toda uma rede de pessoas, que se incluem num movimento vivo e dinâmico de fazer uma educação que assume o tempo presente como uma oportunidade de mudança do "alguns" em "todos", da "discriminação e preconceito" em "reconhecimento e respeito às diferenças" (BRASIL, 2004).

Cumpre ressaltar que a Educação Especial faz parte da rede de apoio das escolas regulares, no que diz respeito às necessidades educacionais especiais. Segundo o Documento Subsidiário à Política de Inclusão (BRASIL, 2005) estas instituições são responsáveis pela realização do levantamento de necessidades específicas da escola; pela elaboração de programas de assessoramento às escolas; pela orientação e supervisão dos agentes da Rede de Apoio à Educação Inclusiva; pela orientação e acompanhamento das famílias de alunos com necessidades educacionais especiais; pela assessoria aos educadores que têm alunos com necessidades educacionais especiais incluídos nas classes comuns do ensino regular e afirma que:

a compreensão da educação como um direito de todos e do processo de inclusão educacional numa perspectiva coletiva da comunidade escolar reforça a necessidade da construção de escolas inclusivas que contam com redes de apoio à inclusão (BRASIL, 2005, p. 5).

Este documento chama a atenção para as práticas discriminatórias observadas no interior das instituições educacionais e levanta o apelo à desinstitucionalização da exclusão.

Uma política efetivamente inclusiva deve ocupar-se com a desinstitucionalização da exclusão, seja ela no espaço da escola ou em outras estruturas sociais. Assim, a implementação de políticas inclusivas que pretendam ser efetivas e duradouras devem incidir sobre a rede de relações que se materializam através das instituições, já que as práticas discriminatórias que elas produzem, extrapolam, em muito, os muros e regulamentos dos territórios organizacionais que as evidenciam (BRASIL, 2005, p. 8).

Com o objetivo de garantir o acesso, a participação e a aprendizagem dos alunos com Deficiência, Transtornos Globais do Desenvolvimento e Altas Habilidades e/ou 
Superdotação nas escolas regulares, foi elaborada a Política de Educação Especial na Perspectiva da Educação Inclusiva (BRASIL, 2008). Este documento expõe a transversalidade da Educação Especial em todos os níveis de ensino:

Na perspectiva da educação inclusiva, a educação especial passa a integrar a proposta pedagógica da escola regular, promovendo o atendimento às necessidades educacionais especiais de alunos com deficiência, transtornos globais do desenvolvimento e altas habilidades/superdotação. Nestes casos e outros, que implicam transtornos funcionais específicos, a educação especial atua de forma articulada com o ensino comum, orientando para o atendimento às necessidades educacionais especiais desses alunos (BRASIL, 2008).

Em 2012 é instituída a Política Nacional de Proteção dos Direitos da Pessoa com Transtorno do Espectro Autista (TEA), através da Lei 12.764, que altera o § 3o do art. 98 da Lei no 8.112, de 11 de dezembro de 1990. Essa lei qualifica a pessoa com TEA, com a seguinte redação:

a) deficiência persistente e clinicamente significativa da comunicação e da interação sociais, manifestada por deficiência marcada de comunicação verbal e não verbal usada para interação social; ausência de reciprocidade social; falência em desenvolver e manter relações apropriadas ao seu nível de desenvolvimento; e, b) padrões restritivos e repetitivos de comportamentos, interesses e atividades, manifestados por comportamentos motores ou verbais estereotipados ou por comportamentos sensoriais incomuns; excessiva aderência a rotinas e padrões de comportamento ritualizados; interesses restritos e fixos.

A Lei 12.764 é regulamentada pelo Decreto 8.368/14 que qualifica a pessoa com TEA como pessoa com deficiência para fins e efeitos legais, o que repercute na aplicabilidade integral das disposições da Lei 13.146/2015, que cria o Estatuto da Pessoa com Deficiência, destinado a assegurar e a promover, em condições de igualdade, o exercício dos direitos e das liberdades fundamentais por pessoa com deficiência, visando à sua inclusão social e cidadania.

Observamos que, a despeito dos avanços gerados por tais documentos, no que tange à compreensão do processo de inclusão em Educação, há um longo caminho a ser trilhado na garantia de direitos à aprendizagem, participação e superação de barreiras atitudinais, pedagógicas e estruturais.

No contexto destas referidas políticas, o TEA ganhou uma maior dimensão social, passou a ter espaço nas salas de recursos multifuncionais e encabeçou a lista das 
prioridades nas necessidades de formação docente dentro de um cenário escolar mais inclusivo.

\section{Processos formativos impulsionados pelos alunos com TEA}

Em pesquisa realizada em 2008, intitulada Inclusão em Educação: um estudo sobre as percepções de professores da rede Estadual de Ensino Fundamental do Rio de Janeiro sobre práticas pedagógicas de inclusão (MELO, 2010), foram realizados encontros com 372 professores do Estado do Rio de Janeiro, separados por regiões coordenadas pelos Núcleos de Apoio Pedagógico Especializado, para um curso de formação sobre o aluno com Transtorno Global do Desenvolvimento (a nomenclatura da época).

O objetivo do curso era o de apresentar a nosologia do transtorno, discutir sobre as características deste e, num momento de oficina, planejar aulas que considerassem a sua presença em sala de aula. Aulas comuns a todos os alunos, mas que alcançassem também o aluno com TEA. Destes encontros foram levantados 92 planos de aula, construídos colaborativamente e pensados para diversas disciplinas e níveis de ensino. Ao avaliarem essa experiência, os professores relataram como vinham trabalhando com seus alunos com TEA dentro do contexto da sala de aula regular. Recorremos a esta pesquisa pois vimos que as falas das professoras mostravam as estratégias pedagógicas existentes no cotidiano escolar, impulsionadas pela presença do aluno com TEA e, com base nelas, refletimos sobre a possibilidade destes professores conhecerem e trabalharem com as tecnologias assistivas como estratégias que podem ser adotadas para aprimorar a educação de todos os alunos. Na referida pesquisa, os professores foram perguntados se em sua sala de aula existia algum aluno com TGD e, se sim, como faziam para desenvolver o processo ensino-aprendizagem:

Pesquiso, pergunto, "dou tiro no escuro", às vezes me surpreendo ao descobrir o quanto eles avançaram, fico com medo de errar, enfim caminho com eles e aprendo mais do que ensino (Bloco de Anexos Avaliação de Professores, linha 2399).

O relato da professora nos remete para um contexto de inseguranças, no qual o trabalho docente se estabelece pelo esforço pessoal e resiliência, assim como a fala abaixo: 
Sim, na verdade, tenho incorrido em estratégias de erros/acertos para estar avaliando cotidianamente qual caminho seguir. Estava me sentindo um pouco perdida e necessitada de ajuda, orientação. Já tinha, de certa maneira, achado o caminho de atividades curtas $e$ mais objetivas, sempre com um momento de "descontração" como brincadeiras, histórias, jogos, etc. (Bloco de Anexos - Avaliação de Professores, linha 6824).

Entendemos que o processo de inclusão em educação pressupõe a participação dos alunos em todas as atividades escolares. Para que isso se efetive, se faz necessário pensar estratégias e práticas pedagógicas de forma coletiva, de modo que os atores escolares sejam responsáveis pelo processo de ensino-aprendizagem de todos os alunos, visto que a presença de estudantes com deficiência na escola tensiona ainda mais os processos de ensino-aprendizagem e de avaliação. Do mesmo modo, o grupo de alunos pode se ajudar, trabalhar juntos como forma de integração, mediação, aprendizagem coletiva, o que, como vimos, parece ser a estratégia usada por alguns professores.

Tenho procurado levar atividades diversificadas para que possa atender as diferentes dificuldades e formo duplas de ajuda com os próprios alunos (Bloco de Anexos - Avaliação de Professores, linha 1718).

O relato acima revela uma forma de enfrentamento do desafio enfrentado pela professora em sala de aula, contudo, acreditamos que a cultura colaborativa ainda é muito incipiente nas escolas e poderia ser mais e melhor trabalhada.

Importante recurso para o processo de inclusão de alunos com TEA, de acordo com Galvão Filho e Miranda (2012), se trata da Tecnologia Assistiva (TA) que é utilizada para ampliar ou possibilitar as possibilidades de aprendizagem de pessoas com deficiência. Acontece que, nas escolas regulares, tal recurso parece ser desconhecido e portanto não utilizado. As professoras não destacam o uso do TA nas práticas pedagógicas relatadas acima, o que nos leva a problematizar a importância de processos formativos que contemplem diferentes recursos e metodologia a fim de atender a diversidade dos nossos alunos. $\mathrm{O}$ excerto seguinte evidencia nossa inquietação:

Sou professora de Educação Física e infelizmente a faculdade não explica sobre o TGD, procuro pesquisar sobre o assunto e usar a criatividade para adaptar atividades (Bloco de Anexos - Avaliação de Professores, linha 2689).

Como professoras universitárias, acompanhamos os desdobramentos dos currículos dos cursos de formação pedagógica e lamentamos o pouquíssimo espaço para 
disciplinas que contemplam a educação inclusiva na formação do professor, que chega à sala de aula despreparado para tanta diversidade.

Galvão Filho e Miranda (2012) afirmam que as tecnologias assistivas buscam favorecer a participação do aluno com deficiência nas diversas atividades do cotidiano escolar, vinculadas aos objetivos educacionais. São exemplos de TA na escola: os materiais escolares e pedagógicos acessíveis, a comunicação alternativa, os recursos de acessibilidade ao computador, os recursos para mobilidade, localização, a sinalização, o mobiliário que atenda às necessidades posturais, entre outros. Tecnologia assistiva é uma expressão utilizada para identificar todo o arsenal de recursos e serviços que contribuem para proporcionar ou ampliar habilidades funcionais de pessoas com deficiência e, consequentemente, promover uma vida mais independente e aumento das possibilidades de participação. De acordo com Bersh e Machado (2007, 31)

Fazer TA na escola é buscar, com criatividade, uma alternativa para que o aluno realize o que deseja ou precisa. É encontrar uma estratégia para que ele possa fazer de outro jeito. É valorizar o seu jeito de fazer e aumentar suas capacidades de ação e interação a partir de suas habilidades. É conhecer e criar novas alternativas para a comunicação, escrita, mobilidade, leitura, brincadeiras, artes, utilização de materiais escolares e pedagógicos, exploração e produção de temas através do computador, etc. É envolver o aluno ativamente, desafiando-se a experimentar e conhecer, permitindo que construa individual e coletivamente novos conhecimentos. É retirar do aluno o papel de espectador e atribuir-lhe a função de ator.

A autora recomenda ainda que devemos conhecer o aluno, sua história, suas necessidades e desejos, bem como identificar quais são as necessidades do contexto escolar, incluindo seu professor, seus colegas, os desafios curriculares e as tarefas exigidas no âmbito coletivo da sala de aula e as possíveis barreiras encontradas que lhe impedem o acesso aos espaços da escola ou ao conhecimento (BERSH; MACHADO, 2007). No relato abaixo, a professora parece se aproximar de tais recomendações:

Faço o acompanhamento de um aluno autista dentro da Educação Inclusiva. Ele tem 4 anos e frequenta o Pré II de uma escola regular. $O$ trabalho é direcionado tanto ao aluno, quanto à professora de classe regular, orientando e proporcionando esclarecimentos $e$ suporte teórico para o trabalho. Com o aluno, objetivamos uma participação cada vez maior nas atividades desenvolvidas $e$ consequente desenvolvimento nas diferentes áreas (Bloco de Anexos Avaliação de Professores, linha 7043). 
A Tecnologia Assistiva (TA) surge, para a pessoa com deficiência como um privilegiado elemento na construção de novos caminhos e possibilidades para o aprendizado e desenvolvimento, na medida em que se situa com instrumento mediador, disponibilizando recursos para superar suas barreiras de aprendizagem e participação e permitindo que esta possa interagir, relacionar-se e competir em seu meio com ferramentas mais poderosas, proporcionadas pelas adaptações de acessibilidade de que dispõe (GALVÃO FILHO, 2012).

Entre os recursos de TA mais significativos no processo de adaptação curricular e superação das barreiras à aprendizagem e participação, podemos mencionar a comunicação aumentativa e alternativa, que de acordo com Bersch e Schirmer (2005, p. 89),

é uma das áreas da TA que atende pessoas sem fala ou escrita funcional ou em defasagem entre sua necessidade comunicativa e sua habilidade em falar e/ou escrever. Busca, então, através da valorização de todas as formas expressivas do sujeito e da construção de recursos próprios desta metodologia, construir e ampliar sua via de expressão e compreensão. Recursos como as pranchas de comunicação, construídas com simbologia gráfica (desenhos representativos de ideias), letras ou palavras escritas, são utilizados pelo usuário da CAA para expressar seus questionamentos, desejos, sentimentos e entendimentos.

Na perspectiva de inclusão escolar, a T.A. não deve se voltar unicamente a promover uma habilidade no aluno, fazendo com que ele realize tarefas como as de seus colegas. A TA será o meio pelo qual esse aluno possa fazer do seu jeito e assim se tornar protagonista de sua história, ativo no seu processo de desenvolvimento e aquisição de conhecimentos (BERSH; MACHADO, 2007).

Em relação aos recursos da TA, entendemos que a comunicação alternativa e ampliada merece especial atenção, visto que a apropriação desse conhecimento possibilita que os professores desenvolvam estratégias que auxiliarão os alunos que possuam dificuldade para se expressar. Dessa forma, a tecnologia assistiva pode dar suporte e orientação para a superação de dificuldades que impedem muitos alunos, com e sem deficiência, de se expressarem (CORTELAZZO, 2012).

O uso da Comunicação Alternativa (CA) como elemento promotor de práticas inclusivas, capaz de propiciar avanços na aprendizagem daqueles que apresentam dificuldades comunicativas, envolve o comprometimento profissional dos professores 
de modo a subsidiar seus conhecimentos e qualificar seus saberes que são plurais e dinâmicos em decorrência do dia a dia de trabalho.

No contexto das T.A., a ênfase nos materiais como gravuras, desenhos, fotos, recortes de revistas e de jornais, oportuniza o desencadeamento de lembranças de fatos, acontecimentos e experiências pessoais, que podem ser vivenciadas pelos alunos. Acreditamos que esta vivência favorece o processo de socialização da turma, mas também, e neste caso, principalmente, favorece a organização e a associação do conhecimento novo aos conhecimentos antigos ou prévios.

De acordo com Ausubel, Novak e Hanesian (1968), a associação dos conhecimentos gera um novo conhecimento, construído a partir das associações feitas pelo aluno, portanto, desenvolvendo a aprendizagem significativa. Ao enfatizarem o trabalho com materiais representativos como gravuras, desenhos, fotos, recortes de revistas e de jornais, os professores demonstram a importância de construir nos alunos o imagens mnêmicas, ou seja, imagens guardadas na memória, passíveis de serem revisitadas. Ressalte-se que estas estratégias não ficariam restritas aos alunos com deficiência, mas contemplaria a todos.

\section{Considerações finais}

Entendemos que, para além das legislações e orientações oficiais, há profunda necessidade de repensar as culturas, políticas e práticas institucionais no que tange à formação e ao papel docente. O papel do professor é fundamental para promover o processo de inclusão e os alunos com TEA são atores que desencadeiam tal processo, pois viabilizam e desafiam a escola e o processo educacional.

Investir em inovações pedagógicas e tecnológicas é um caminho profícuo na tentativa de criar respostas às indagações apresentadas pela diversidade de nossos alunos com e sem deficiência, mas as mudanças de práticas pedagógicas precisam estar associadas à construção de novos valores, concepções e crenças (culturas) e de políticas institucionais, que se esforcem para efetuar o direito à educação compreendendo o ser humano em sua integralidade, que se traduz no acolhimento de suas singularidades e diferenças, o que certamente poderia trazer as mudanças que as escolas e seus atores têm sido convocados a realizar.

\section{REFERÊNCIAS}


AMERICAN PSYCHIATRIC ASSOCIATION. Diagnostic and Statistical Manual of Mental Disorders, Fifth Edition (DSM-V). Arlington, VA: American Psychiatric Association, 2013.

AMY, M. D. Enfrentando o autismo: a criança autista, seus pais e a relação terapêutica. Rio de Janeiro: Jorge Zahar Editor, 2001.

AUSUBEL, D.; NOVAK, J.; HANESIAN, H. Psicologia Educacional. Interamericana. 1968.

BAPTISTA, C.; BOSA, C. Autismo e educação. Porto Alegre: Artmed, 2002.

BERQUEZ, G. L'autisme Infantile. Introduction à une clinique relationnelle selon Kanner. Paris, Presses Universitaires de France, 1983.

BERSCH, R.; SCHIRMER, C. Tecnologia Assistiva no Processo Educacional. IN.: Ensaios Pedagógicos: Construindo Escolas Inclusivas. Brasília: MEC/SEESP, 2005.

BERSCH, R.; MACHADO, R. In: SCHIRMER, Carolina R. et al.

Atendimento Educacional Especializado - Deficiência Física. Brasília/DF:

MEC/SEESP, 2007. 129p. Disponível em:

http://portal.mec.gov.br/seesp/arquivos/pdf/aee_df.pdf. Acesso em: 13 jun. 2018.

\section{BRASIL. MJ/CORDE. Declaração de Salamanca e Linhas de Ação sobre}

Necessidades Educativas Especiais. Brasília: CORDE, 1994.

BRASIL. Documento Subsidiário à Política de Inclusão. MEC, Produtor \& Secretaria de Educação Especial, 2005. Disponível em:

http://portal.mec.gov.br/seesp/arquivos/pdf/livro\%20educacao\%20inclusiva.pdf. Acesso em: 03 ago. 2018.

BRASIL. Lei de Diretrizes e Bases da Educação Nacional. Lei nº 9394/20.12.96.

Brasília, DF, Brasil: Saraiva, 1996.

BRASIL. O Acesso de Alunos com Deficiência às Escolas e Classes Comuns da Rede Regular. Ministério Público Federal - Fundação Procurador Pedro Jorge Silva (org.), 2004. Disponível em: http://www.adiron.com.br/arquivos/cartilhaatual.pdf. Acesso em: 03 set. 2018.

\section{BRASIL. Política Nacional da Educação Especial na Perspectiva da Educação} Inclusiva. Brasília, 2008. Disponível em http://portal.mec.gov.br/index.php?option=com_docman\&view=download\&alias=1669 0-politica-nacional-de-educacao-especial-na-perspectiva-da-educacao-inclusiva05122014\&Itemid=30192. Acesso em: 03 set. 2018.

BRASIL. Lei 12.764 de 11/12/20122 - Institui a Política Nacional de Proteção dos Direitos da Pessoa com Transtorno do Espectro Autista; e altera o § 3o do art. 98 da Lei no 8.112, de 11 de dezembro de 1990. Disponível em:

presrepublica.jusbrasil.com.br/legislacao/1033668/lei-12764-12. Acesso em: 03 set. 2018. 
BRASIL. Decreto no 8.368, de 02/12/2014 - Regulamenta a Lei 12.764, de 11/12/2012. Disponível: http://www.planalto.gov.br/CCIVIL_03/_Ato20112014/2014/Decreto/D8368.htm. Acesso em: 03 set. 2018.

BRASIL. Lei 13.146 de 06/07/2015 - Institui a Lei Brasileira de Inclusão da Pessoa com Deficiência. Disponível: http://www.planalto.gov.br/ccivil_03/_Ato20152018/2015/Lei/L13146.htm. Acesso em: 03 set. 2018.

CORTELAZZO, I. B. C. Formação de professores para uma educação inclusiva mediada pelas tecnologias. In: GIROTO, C. R. M.; POKER, R. B.; OMOTE, S. (Orgs.). As tecnologias nas práticas pedagógicas inclusivas. Marília: Oficina Universitária; São Paulo: Cultura Acadêmica, 2012, p. 93-120.

FACION, J. R.; MARINHO, V.; RABELO, L. Transtorno autista. In: FACION, J. R (Ed.). Transtornos invasivos do desenvolvimento associados a graves problemas do comportamento: reflexões sobre um modelo integrativo. Brasília, DF: Corde, 2002. p. 23-38.

GALVÃO FILHO, T. A.; MIRANDA, T. G. Tecnologia Assistiva e salas de recursos: análise crítica de um modelo. In: GALVÃO FILHO, T. A. (Org.); MIRANDA, T. G. (Org.). O professor e a educação inclusiva: formação, práticas e lugares. Salvador: Editora da Universidade Federal da Bahia - EDUFBA, 2012, p. 247-266.

KANNER, L. Autistic Disturbances of Affective Contact. Nervous Child, n. 2, 1943, p.217-250.

MELO, S. C. Inclusão em educação: um estudo sobre as percepções de professores da rede Estadual de Ensino Fundamental do Rio de Janeiro, sobre práticas pedagógicas de inclusão. Tese (Doutorado em Educação), Faculdade de Educação, Universidade Federal do Rio de Janeiro, 2010.

MELLO, M. L. S. Registros de aula: espaços de estudo sobre o currículo. Tese (Doutorado em Educação) - Faculdade de Educação, Universidade do Estado do Rio de Janeiro, Rio de Janeiro, 2007.

PERRENOUD, P.; PAQUAY, L.; ALTET, M.; CHARLIER, É. (orgs.). Formando professores profissionais: Que estratégia? Que competência. Porto Alegre, RS: Artmed Editora, 2001.

RIVIÈRE, Á. O autismo e os transtornos globais do desenvolvimento. In: COLL, C.; MARCHESI, A.; PALACIOS, J. (Org.). Desenvolvimento psicológico e educação. 2. ed. Porto Alegre: Artmed, 2004. v. 3, p. 234-254.

\section{Como referenciar este artigo}

CORDEIRO DE MELO, Sandra; SANTIAGO, Mylene Cristina. Título. Revista on line de Política e Gestão Educacional, Araraquara, v. 22, n. esp. 2, p. 890-904, dez., 2018. EISSN:1519-9029. DOI: 10.22633/rpge.unesp.v22.nesp2.dez.2018.11919 